\title{
Sources and resources: importance of nutrients, resource allocation, and ecology in microalgal cultivation for lipid accumulation
}

\author{
Matthew W. Fields • Adam Hise • Egan J. Lohman • Tisza Bell • Rob D. Gardner • \\ Luisa Corredor • Karen Moll • Brent M. Peyton • Gregory W. Characklis • Robin Gerlach
}

Received: 27 January 2014 /Revised: 13 March 2014 / Accepted: 14 March 2014 / Published online: 3 April 2014

(C) The Author(s) 2014. This article is published with open access at Springerlink.com

\begin{abstract}
Regardless of current market conditions and availability of conventional petroleum sources, alternatives are needed to circumvent future economic and environmental impacts from continued exploration and harvesting of conventional hydrocarbons. Diatoms and green algae (microalgae) are eukaryotic photoautotrophs that can utilize inorganic carbon (e.g., $\mathrm{CO}_{2}$ ) as a carbon source and sunlight as an energy source, and many microalgae can store carbon and energy in the form of neutral lipids. In addition to accumulating useful precursors for biofuels and chemical feed stocks, the use of autotrophic microorganisms can further contribute to reduced $\mathrm{CO}_{2}$ emissions through utilization of atmospheric $\mathrm{CO}_{2}$. Because of the inherent connection between carbon, nitrogen, and phosphorus in biological systems, macronutrient deprivation has been proven to significantly enhance lipid accumulation in different diatom and algae species. However, much work is needed to understand the link between carbon, nitrogen, and phosphorus in controlling resource allocation at different levels of biological resolution (cellular versus ecological). An improved understanding of
\end{abstract}

M. W. Fields $(\bowtie) \cdot$ T. Bell $\cdot$ L. Corredor $\cdot$ K. Moll

Department of Microbiology and Immunology, Montana State University, 109 Lewis Hall, Bozeman, MT 59717, USA

e-mail: matthew.fields@erc.montana.edu

A. Hise $\cdot$ G. W. Characklis

Department of Environmental Sciences and Engineering,

University of North Carolina, Chapel Hill, NC, USA

M. W. Fields • E. J. Lohman • T. Bell • R. D. Gardner • L. Corredor • K. Moll • B. M. Peyton · R. Gerlach

Center for Biofilm Engineering, Montana State University,

Bozeman, MT, USA

E. J. Lohman • B. M. Peyton • R. Gerlach

Department of Chemical and Biological Engineering,

Montana State University, Bozeman, MT, USA the relationship between the effects of $\mathrm{N}, \mathrm{P}$, and micronutrient availability on carbon resource allocation (cell growth versus lipid storage) in microalgae is needed in conjunction with life cycle analysis. This mini-review will briefly discuss the current literature on the use of nutrient deprivation and other conditions to control and optimize microalgal growth in the context of cell and lipid accumulation for scale-up processes.

Keywords Biofuel $\cdot$ Recycle $\cdot$ Algal biofilm $\cdot$ Biofuel ecology

\section{Introduction}

In modern societies, petroleum-based products and fuels have strongly influenced human culture and infrastructure. For example, energy, food, and chemicals make up approximately $70 \%$ of commerce on the planet (www.eia.gov), and petroleum/hydrocarbons directly and indirectly impact these commodities. Petroleum/hydrocarbon markets have become increasingly unpredictable and cause destabilized commodity prices (e.g., fuel, food). In addition, the environmental impacts from increased carbon dioxide $\left(\mathrm{CO}_{2}\right)$ without balanced $\mathrm{CO}_{2}$ sequestration has contributed to increases in atmospheric $\mathrm{CO}_{2}$ levels. The amount of carbon released in 1 year from the consumption of fossil fuels is more than 400-fold the amount of carbon that can be fixed via net global primary productivity (Dukes 2003). In order to offset the massive influx of $\mathrm{CO}_{2}$ into the atmosphere, the utilization of renewable biofuels (e.g., ethanol, butanol, $\mathrm{H}_{2}, \mathrm{CH}_{4}$, and biodiesel) is needed.

Bacillariophyta (diatoms) and Chlorophyta (green algae) are eukaryotic photoautotrophs that can utilize inorganic carbon (e.g., $\mathrm{CO}_{2}$ ) as a carbon source and sunlight as an energy source, and many microalgae can store carbon and energy in the form of neutral lipids [e.g., triacylglycerides (TAGs)]. 
Moreover, different diatoms and algae can produce and accumulate different precursors (e.g., carbohydrates, fatty acids, and pigments) that are value-added products. In addition to accumulating useful compounds for biofuels and chemical feed stocks, the use of autotrophic microorganisms can further contribute to reduced $\mathrm{CO}_{2}$ emissions through utilization of atmospheric $\mathrm{CO}_{2}$. For these reasons, eukaryotic photoautotrophs have been studied in the context of lipid accumulation for over 50 years and were a focus of the US Department of Energy's Aquatic Species Program in the 1980s and 1990s (Sheehan 1998). However, low petroleum prices eventually eroded monetary support for alternative (and renewable) energy sources until increasing petroleum prices over the last two decades reinvigorated interest in alternatives.

The advent and increased use of fracking technologies has opened up new petroleum and hydrocarbon reservoirs, and almost $\$ 190 \times 10^{9}$ was spent in the USA in 2012 to drill and "frac" for conventional hydrocarbons (www.eia.gov). However, the process of fracking increases the production rate and not the ultimate supply of hydrocarbons, and peak hydrocarbon production is predicted to occur around 2030 (www.eia.gov). Regardless of current market conditions and availability of conventional sources, alternatives are needed to circumvent future economic and environmental impacts from continued exploration and harvesting of conventional hydrocarbons.

Conservative estimates predict (assuming a lipid content of $25-30 \%(w / w)$ in microalgae) that an area equivalent to $3 \%$ of the arable cropland in the USA would be required to grow sufficient microalgae to replace $50 \%$ of the transportation fuel needs in the USA (Chisti 2007; Georgianna and Mayfield 2012). Although the interest in algal biofuels has been reinvigorated (Courchesne et al. 2009; Greenwell et al. 2010; Razghefard 2013), significant fundamental and applied research is still needed to fully maximize algal biomass and biochemical production for biofuels and other products.

The accumulation of lipids is of substantial interest because these compounds are energy-rich biodiesel precursors (Dismukes et al. 2008; Hu et al. 2008). Much of the reported research has focused on increasing algal lipid accumulation upon exposing cultures to a range of environmental stresses prior to harvest (Hu et al. 2008; Valenzuela et al. 2012, 2013; Mus et al. 2013; Lohman et al. 2013; references therein). Temperature variations, $\mathrm{pH}$, salinity, light, and osmotic and chemical stress inducements have also been investigated with varying success (Sharma et al. 2012). While a stress event can increase lipid accumulation, it can also limit biomass production, but the stress scenario provides a tractable method to study and understand lipid accumulation at the laboratory scale (Valenzuela et al. 2013). Because of the inherent connection between carbon $(\mathrm{C})$, nitrogen $(\mathrm{N})$, and phosphorus $(\mathrm{P})$ in biological systems, macronutrient deprivation has been proven to significantly enhance lipid accumulation in different diatom and algae species. While nitrogen limitation is the most commonly studied stress in green algae and diatoms; the effect of silica limitation is regularly studied in diatoms (Valenzuela et al. 2012; Lohman et al. 2013; Chu et al. 2013; Schnurr et al. 2013). Light and temperature are also known stressors that can impact lipid accumulation (Hu et al. 2008), and particular wavelengths have been shown to impact the rate and amount of accumulated lipid in Chlorella (Atta et al. 2013). Keeping in mind that a vast majority of living pools of $\mathrm{C}, \mathrm{N}$, and $\mathrm{P}$ resides in the microbial realm (Whitman et al. 1998), much work is needed to understand the link between C, $\mathrm{N}$, and $\mathrm{P}$ in controlling resource allocation both with respect to natural and man-made systems. In this context, a $50 \%$ replacement of transportation fuel by renewable biological sources would impose a vast nutrient demand (Pate et al. 2011). However, microalgal biomass/product production can be coupled to wastewater resources (e.g., water, $\mathrm{N}$, and $\mathrm{P}$ ), and wastewater from agricultural, industrial, and municipal activity may provide a cost-effective source of nutrients. Agricultural and municipal wastewater can be high in $\mathrm{N}$ and $\mathrm{P}$ (Aslan and Kapdan 2006; Hoffmann 2002; Mallick 2002; Pittman et al. 2011), and thus, there is a great potential for the integration of wastewater treatment and algal biofuel/biomass production (Fig. 1). However, an improved understanding of the relationship between the effects of $\mathrm{N}, \mathrm{P}$, and micronutrient availability on cellular resource allocation (cell growth versus lipid storage) in microalgae is needed. This mini-review will briefly discuss the current literature on the use of nutrient deprivation and other conditions to control and optimize microalgal culture growth in the context of cell and lipid accumulation.

\section{Nutrient-dependent lipid accumulation}

Under optimal growth conditions, (i.e., adequate supply of nutrients including $\mathrm{C}, \mathrm{N}, \mathrm{P}$, and sunlight), algal biomass

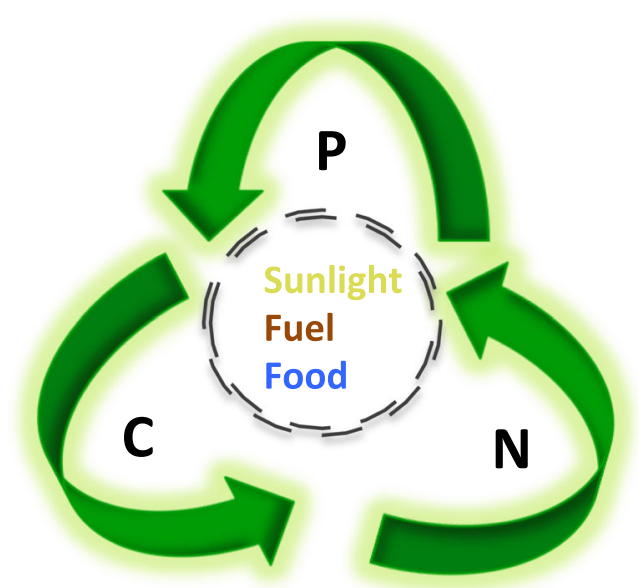

Fig. 1 The biological recycling of carbon, nitrogen, and phosphorus to harvest fuel and food linked to sunlight to reduce net consumption of $\mathrm{N}$ and $\mathrm{P}$ and net production of $\mathrm{C}$ 
productivity can exceed $30 \mathrm{~g}$ dry weight per square meter per day (Gordon and Polle 2007); however, the lipid content of the biomass is typically very low $(<5 \% w / w)$ and is speciesdependent (Gordon and Polle 2007). The low-lipid content is due to lipid biosynthesis being a metabolic process that is typically stimulated by stress inducement. Essentially, biomass synthesis and lipid biosynthesis compete for photosynthetic assimilation of inorganic carbon, and a fundamental metabolic switch is required to shift from biomass production to energy storage metabolism (Schuhmann et al. 2012; Valenzuela et al. 2012). As denoted by Odum (1985), stress is a syndrome that consists of inputs and outputs, and the input is the stressor that is contrasted to the stress, or the output. Lipids (the output) are typically believed to provide a storage function within the cell that enables the organism to endure adverse environmental conditions, i.e., the stressor. The output can be viewed as the cessation of cell production and the accumulation of lipids in response to the input of unbalanced resources (e.g., N, P, and/or sunlight). It is likely that there are tradeoffs in terms of biomass versus lipid accumulation depending on the different levels of perturbation (Fig. 2).

Recent research has provided evidence that lipids may also act as a reservoir for specific fatty acids such as polyunsaturated fatty acids (PUFAs) (Ratha et al. 2013). PUFAs play a key role in the structural components of cell membranes, and as antioxidants (PUFAs can counteract free radical formation during photosynthesis). As such, PUFA-rich TAGs might donate specific compounds necessary to rapidly reorganize membranes through adaptive metabolic responses to sudden changes in environmental conditions (Khozin-Goldberg and Cohen 2006). However, a recent study showed that PUFA content in lipids can negatively impact biodiesel quality based upon lipids from Chlorella pyrenoidosa (Shekh et al. 2013), and this result suggests that lipid composition, and not just amounts, should be considered. In either case, lipid is an energy-rich storage compound that can be chemically transesterified to produce fatty acid methyl esters (FAME), the biological equivalent to diesel fuel (a.k.a., biodiesel). However, to maximize lipid biosynthesis, the producing organism is typically induced through environmental stress conditions (Hu et al. 2008). In addition, most studies have been based upon axenic cultures with limited understanding of potential bacterial "contamination," and thus, lipid accumulation may be different at different scales of biological resolution (discussed below).

Significant work has been done to identify and optimize stress-inducement strategies that enhance lipid accumulation in microalgal species. Nutrient deprivation, specifically nitrogen depletion, is the most prevalent technique employed (Hu et al. 2008). This may be due to two factors: (1) Lack of requisite nutrients such as nitrogen limits the capacity to synthesize proteins necessary for biomass production (e.g., cellular division). In order to compensate, the organism must take advantage of alternative metabolic pathways for inorganic carbon fixation, such as fatty acid synthesis and hence, store those de novo fatty acids as TAG (Msanne et al. 2012). (2) Photosynthesis and the electron transport chain in eukaryotic microalgae produce ATP and NADPH as energy "storage" and electron carrier metabolites, respectively (Halsey et al. 2013). These metabolites are consumed during biomass production resulting in ADP and $\mathrm{NADP}^{+}$, which in turn, are regenerated via photosystems. Under normal growth conditions, this cycle maintains a balanced ratio of the reduced and oxidized forms of these metabolites; however, when biomass production is impaired due to a lack of requisite nutrients, the pool of $\mathrm{NADP}^{+}$ and ADP can become depleted. This can lead to a potentially dangerous situation for the cell because photosynthesis is mainly controlled by light availability, and cannot be shut off completely. Fatty acid synthesis consumes NADPH and ATP; therefore, increased fatty acid synthesis replenishes the pool of
Fig. 2 Hypothetical performance curve for an increasingly perturbed (i.e., stressed) microalgal system being used to produce photoautotrophic biomass and/or lipids. Adapted from Odum et al. (1979)

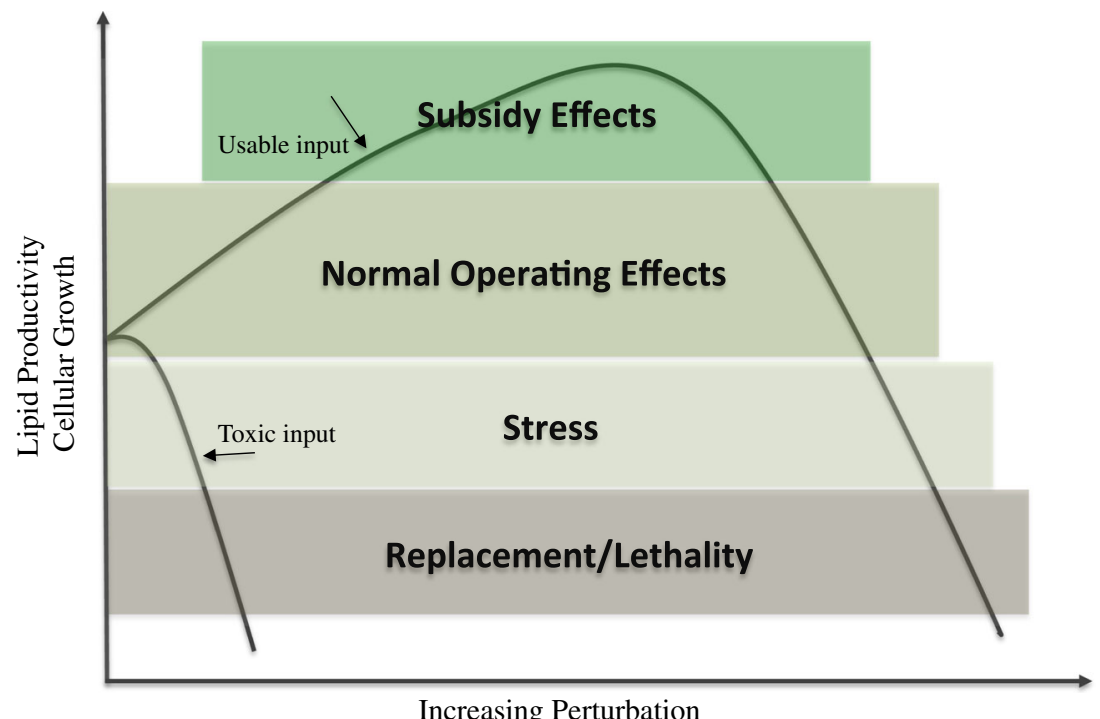

Increasing Perturbation 
required electron acceptors in the form of $\mathrm{NADP}^{+}$, and de novo fatty acids are most frequently stored as lipid (Brown et al. 2009). Here, we will review the most successful strategies involving nutrient stress to induce lipid accumulation in commonly studied microalgal species.

\section{Nitrogen and phosphorus}

Nutrient availability is critical for cell division and intracellular metabolite cycling, and once nutrients such as $\mathrm{N}$ or $\mathrm{P}$ become depleted or limited in the medium, invariably, a steady decline in cellular reproduction rate ensues. Once this occurs, the activated metabolic pathways responsible for biomass production are down-regulated and cells instead divert and deposit much of the available $\mathrm{C}$ into lipid (Wang et al. 2009; Valenzuela et al. 2013). There have been numerous studies to compare different $\mathrm{N}$ sources in the context of maximal biomass or lipid accumulation, and the results are different dependent upon the organism. Breuer et al. (2012) accumulated previous literature on 56 eukaryotic, photoautotrophic genera studied in the context of lipid accumulation (Table 1). The authors chose Chlorella vulgaris, Chlorella zofingiensis, Nannochloris UTEX 1999, Neochloris oleoabundans, Scenedesmus obliquus, Dunaliella tertiolecta, Isochrysis galbana, Phaeodactylum tricornutum, and Prophyridium cruentum to conduct normalized growth and lipid accumulation studies with nitrate as the $\mathrm{N}$ source (Breuer et al. 2012). Under $\mathrm{N}$ deprivation, Chlorella vulgaris, Chlorella zofingiensis, Neochloris oleoabundans, and Scenedesmus obliquus accumulated over $35 \%$ dry weight as TAG, and Scenedesmus obliquus and Chlorella zofingiensis had the highest TAG productivity $\left(240-320 \mathrm{mg} \mathrm{L}^{-1}\right.$ day $^{-1}$ ) among the nine compared strains.

Table 1 Genera of 56 eukaryotic, photoautotrophs previously studied and reported for the accumulation of lipids. Modified from Breuer et al. (2012)

\begin{tabular}{llll}
\hline Amphora & Ankitrodesmus & Biddulphia & Botryococcus \\
Bracteacoccus & Chaetoceros & Chlamydomonas & Chlorella \\
Chlorococcum & Chroomonas & Cryphecodinium & Cryptomonas \\
Cylindrotheca & Dictyosphaerium & Dunaliella & Ellipsoidion \\
Emuliania & Enteromorpha & Euglena & Fragilaria \\
Glossomastrix & Gymnodinium & Haematococcus & Hantzchi \\
Hemiselmis & Isochrysis & Monallantus & Monodus \\
Nannochloris & Nannochloropsis & Navicula & Neochloris \\
Nephroselmis & Nitzschia & Ochromonas & Parietochloris \\
Pavlova & Phaeodactylum & Pheomonas & Polytoma \\
Porphyridium & Protosiphon & Prototheca & Rhodomonas \\
Rhodosorus & Scenedesmus & Scrippsiella & Selenastrum \\
Skeletonema & Stichococcus & Tetraselmis & Thalassiosira \\
Ulothirx & Vlvox & & \\
\hline
\end{tabular}

When the model Chlorophyte Chlamydomonas reinhardtii was cultivated under $\mathrm{N}$ limitation, an increase in lipid was also observed. Interestingly, fully saturated $\mathrm{C}_{16}$ fatty acids were the most abundantly synthesized compounds, whereas polyunsaturated $\mathrm{C}_{18}$ fatty acids remained relatively unchanged in this organism under the tested conditions (Lohman et al. 2013). While nitrate supported increased biomass compared to ammonium in Monoraphidium sp. SB2 (Wu et al. 2013), Chlorococcum ellipsoideum exhibited elevated lipid levels with urea compared to nitrate ( $\mathrm{Li}$ et al. 2013). A different Scenedesmus strain (sp. R-16) was shown to have the highest lipid accumulation with nitrate compared to urea, peptone, or yeast extract (Ren et al. 2013). To date, nitrate is a commonly studied $\mathrm{N}$ source used to understand nutrient deprivation to induce lipid accumulation; however, different $\mathrm{N}$ sources have different effects dependent upon the organism. This is most likely a consequence of typical habitat for the organism as well as long-term life history that is common for the respective species. As the need for nutrient recycling becomes more evident, different types and mixtures of nutrients (e.g., human, agriculture, industrial) must continue to be evaluated. For example, two recent studies investigated the ability of Chlamydomonas polypyrenoideum and Chlorella pyrenoidosa to grow and accumulate lipids during cultivation on dairy wastewater (Kothari et al. 2012, 2013), and we recently grew a green alga isolated from storage ponds of coal-bed water that produced lipids under nutrient deprivation (Fields, Nagy, and Barnhart, unpublished results). Nitrogen deprivation was shown to induce lipid accumulation in the wastewater isolates, Scenedesmus sp. 131 and Monoraphidium sp. 92 with ammonium, nitrate, or urea (Eustance et al. 2013) or nitrate depletion in Skeletonema marinoi (Bertozzini et al. 2013). Interestingly, Ettlia oleoabundans initiated lipid accumulation in response to increased temperature before nitrate was completely depleted (Yang et al. 2013). These results suggest that different combinations of potential stressors could impact lipid accumulation in different ways.

In addition to N, P starvation to induce lipid accumulation in microalgae has been studied as a sole stress or in combination with $\mathrm{N}$ limitation. In general, greater lipid accumulation due to $\mathrm{N}$ deprivation has been observed compared to $\mathrm{P}$ deprivation as reported for various Chlorella species (Feng et al. 2012; Liang et al. 2012). When the marine diatom Phaeodactylum tricornutum was grown under $\mathrm{N}$ and $\mathrm{P}$ limitation, an increase in lipid accumulation was noticed in all limiting conditions (Valenzuela et al. 2012; Burrows et al. 2012). However, cultures of Phaeodactylum tricornutum that were limited exclusively in $\mathrm{N}$ showed a more significant increase in TAG than cultures that were limited solely in P. The combined limitation of both $\mathrm{N}$ and $\mathrm{P}$ resulted in the highest lipid concentrations in Phaeodactylum tricornutum (Valenzuela et al. 2012, 2013). Given the commonly accepted N/P ratio of 16:1 in microalgal biomass (Redfield 1958), the 
Phaeodactylum tricornutum work demonstrated that the external N/P ratio was 27 and the cellular N/P ratio was between 8:1 and 9:1 when lipid accumulation was observed (Valenzuela et al. 2012).

Both $\mathrm{N}$ and $\mathrm{P}$ deprivation result in cell cycle cessation, but the relative lipid accumulation response is different, and this observation is most likely a consequence of cellular resource allocation (e.g., protein/chlorophyll vs. nucleotides). Based upon results in Phaeodactylum tricornutum, we observed a fivefold greater increase in specific fluorescence of Nile Red, a commonly used indicator of lipid accumulation (Gardner et al. 2011), when cells were depleted of nitrate compared to cells depleted of phosphate. In addition, resupplementation of $\mathrm{N}$ or $\mathrm{P}$ promoted cellular growth, cessation of lipid accumulation, and increased lipid consumption in Phaeodactylum tricornutum (Valenzuela et al. 2013).

\section{Carbon}

It is important to keep in mind that when comparing different nutrient-deprived states, carbon, above all else, is absolutely required for lipid biosynthesis (Palmqvist et al. 1988; Spalding 2008). Without carbon, independent of nutrient deprivation, biomass or lipid biosynthesis is impossible. Therefore, the most successful reports of lipid induction techniques in microalgal lipid production typically involve elevated concentrations of inorganic carbon in tandem with $\mathrm{N}$ and/or $\mathrm{P}$ limitation (Gardner et al. 2011, 2012; Sharma et al. 2012). These strategies often employ a $\mathrm{CO}_{2}$ sparge to increase dissolved $\mathrm{CO}_{2}$ above atmospheric concentrations, or addition of soluble inorganic carbon during inoculation or just prior to nutrient depletion (Gardner et al. 2011, 2012). It should be kept in mind that the addition of soluble inorganic carbon (e.g., bicarbonate) can also affect $\mathrm{pH}$ and osmolarity. The addition of large amounts of dissolved inorganic carbon via a $\mathrm{CO}_{2}$ gas sparge can contribute significantly to the production cost in an algal biorefinery (e.g., Liu et al. 2013), and alternative methods to gaseous $\mathrm{CO}_{2}$-based carbon supply should be considered in conjunction with $\mathrm{pH}$ control. Gardner et al. (2011, 2012) demonstrated that the dosage of small amounts of bicarbonate, solely or in combination with a $\mathrm{CO}_{2}$ sparge, can achieve similar algal growth and lipid production yields compared to continuous $\mathrm{CO}_{2}$ sparging. The use of bicarbonate addition, versus $\mathrm{CO}_{2}$ sparging, could result in significantly lower equipment costs. In either case, elevated concentrations of $\mathrm{C}$, combined with $\mathrm{N}$ or other nutrient deprivation, has been shown to induce lipid accumulation in virtually every microalgal species tested. However, an improved understanding of cellular and population responses to not only the respective concentrations but the ratios of macronutrients (e.g., $\mathrm{C}, \mathrm{N}$, and $\mathrm{P}$ ) will improve resource utilization and promote efficient, cost-effective processes.

\section{Silicon limitation}

Reports on silicon limitation have revealed that both marine and freshwater diatoms will accumulate lipid under Silimiting conditions (Sharma et al. 2012), and diatoms possess immense potential as contributors to biodiesel production. When faced with Si-limitations, most diatoms appear to direct carbon storage towards lipid (Roessler 1988), albeit the response is dependent on the degree of $\mathrm{Si}$ content in the cell wall. Diatoms incorporate biologically available Si as monomeric or dimeric silicic acid into silicious cell walls (frustules) and require approximately $7 \%$ of the energy expenditure required for polysaccharide cell wall formation characteristic of green algae (Hildebrand et al. 2012; Kroger and Poulsen 2008; Raven 1983). Diatoms produce comparatively less cellular starch, such that fixed carbon has increased potential to be allocated to lipid accumulation (Burrows et al. 2012; Gardner et al. 2011; Roessler 1988; Smith et al. 2012). In fact, diatom cells can accumulate enough TAG to cause the frustules to break under silica deplete conditions (Hildebrand et al. 2012), potentially reducing the need for energy intensive procedures associated with lipid extraction in green algae.

Numerous studies have shown increased lipid accumulation when diatoms are cultured in silica deplete media (Lombardi and Wangersky 1991; McGinnis et al. 1997; Obata et al. 2013; Yu et al. 2009). However, the majority of these studies were performed on marine diatoms (e.g., Cylindrotheca spp., Thalassiosira pseudonana, and Phaeodactylum tricornutum) grown in media containing comparatively lower silica concentrations (Taguchi et al. 1987; Roessler 1988; Yu et al. 2009). The results of Moll et al. (2014) indicate that increasing the silica concentration will increase cell numbers, which is vital for improving algal biodiesel productivity in terms of increased biomass. Therefore, while research on marine diatoms for use in biofuel applications may be advantageous for use in large-scale raceway ponds due to the ability to tolerate saline environments, the actual use may be limited until conditions are optimized for diatom cell growth and lipid accumulation.

While silica limitation is known to increase lipid accumulation, combined with other physiological stresses, lipid accumulation may be enhanced. A recent study investigated the effect of coincident silica and nitrate limitation and $\mathrm{HCO}_{3}{ }^{-}$ addition to promote lipid accumulation in a freshwater diatom. Moll et al. (2014) observed that combined silica and nitrate limitation, as well as sodium bicarbonate addition increased lipid accumulation compared to individual stressors with or without $\mathrm{HCO}_{3}{ }^{-}$. One hypothesis for this observation is the effect on the cell cycle. Olson et al. (1986) and Vaulot et al. (1987) revealed that for Thalassiosira weisflogii and Hymenomonas carterae, nitrate and silica limitation resulted in halting the cell cycle at $G_{1}$ and the $G_{1} / S$ and $G_{2} / M$ boundaries, respectively (Darley and Volcani 1969). It is possible 
that the two combined nutrient limitations at different periods within the cell cycle may contribute to cellular stress and ultimately lead to enhanced lipid accumulation in diatoms.

\section{Iron limitation}

As mentioned above, $\mathrm{N}, \mathrm{P}$, and $\mathrm{C}$ are the most important macronutrients, but $\mathrm{Fe}$ is the most versatile and important trace element for biochemical catalysis. Approximately 30 to $40 \%$ of the world's oceans are iron limited, and studies have investigated "iron fertilization" experiments whereby iron is added to high-nutrient low chlorophyll (HNLC) areas to induce phytoplankton growth and $\mathrm{CO}_{2}$ fixation (Buesseler et al. 2004). Iron-limited conditions are thought to alter cell physiology by reducing cell volume, chlorophyll content, and photosynthetic activity, and thus appear to impact cellular accumulation more than lipid accumulation per se. Specifically in Phaeodactylum tricornutum, the following enzymes were down-regulated during iron-starvation: $\beta$-carbonic anhydrase, phosphoribulokinase (PRK), two RuBisCO enzymes and a $\mathrm{HCO}_{3}{ }^{-}$transporter, likely resulting in decreased carbon fixation and cellular growth (Allen et al. 2008). The results suggest that iron limitation greatly impacts cell growth and accumulation, and that approximately $10 \mu \mathrm{mol} \mathrm{Fe} / \mathrm{mol} \mathrm{C}$ is needed by marine algae (Morel et al. 1991). Iron limitation has also been linked to increased rates of silicification, thus increasing cell density and cell sinking. According to Allen et al. (2008), cells grown under Fe-limited conditions fixed carbon 14 times slower compared to cells grown in iron-replete conditions. Since iron limitation can result in detrimental physiological effects, it is pertinent to determine the potential for these processes to be useful for commercial scale lipid accumulation.

\section{Biofilm growth}

One of the most significant limitations to the economical use of algae is the high cost of harvesting and concentrating the biomass (Johnson and Wen 2010; Christenson and Sims 2012; Ozkan et al. 2012; Schnurr et al. 2013; Bernstein et al. 2014). To date, research has been focused on microalgae in suspended phase for lipid production, and few studies have focused on the biofilm growth state. However, the biofilm growth state provides some advantages over suspended growth systems in terms of biomass accumulation and maintenance that would be beneficial for biomass harvesting and concentrating prior to processing. Algal suspensions are often between 0.02 and $0.06 \%$ total suspended solids (TSS), and significant energy is required to harvest and concentrate the cells to 5 to $25 \%$ TSS. Biofilms can range from 6 to $16 \%$ TSS (Schnurr et al. 2013), and could potentially minimize biomass-processing costs (Johnson and Wen 2010; Christenson and Sims 2012; Ozkan et al. 2012). In general, the available algal biofilm studies are based upon wastewater treatment, biofilm structure and development, and aquaculture applications (Johnson and Wen 2010; Christenson and Sims 2012; Patil and Anil 2005; Irving and Allen 2011; AvendañoHerrera and Riquelme 2007). There is a small amount of research on biofilm systems for the production of biomass and lipids in eukaryotic photoautotrophs (Schnurr et al. 2013; Bernstein et al. 2014), but very little in relation to the influence of environmental stresses.

Recently, Schnurr et al. (2013) reported biofilm growth under nutrient starvation to stimulate lipid accumulation. A semi-continuous flat plate parallel horizontal photobioreactor system (PBR) was designed to control the bulk medium nitrogen and silicon concentrations until nutrient depletion and biofilm onset. Wastewater was used to seed biofilm growth and was later replaced by synthetic medium and pure cultures of Nitzschia palea and Scenedesmus obliquus. Wellattached, thick algal biofilms were observed in all experiments, until $\mathrm{N}$ and $\mathrm{Si}$ levels decreased to below detection limits, resulting in detachment from the substratum. In contrast to suspended algae, the algal biofilms did not accumulate more neutral lipids when exposed to nutrient-deficient conditions in these studies. Similar results were reported by Bernstein et al. (2014) who observed little lipid accumulation in mixed culture wastewater biofilms on the field scale or in laboratory-scale algal biofilm reactors seeded with a Botryococcus sp. (strain WC2B). Based upon these results, there appears to be fundamental differences in the way suspended cultures and biofilm cultures respond to nutrient deprivation. The exact reasons for differences between suspended and biofilm cells are unknown, but may be a consequence of altered nutrient cycling in biofilms due to altered carbon flow for cellular turnover and compound accumulation. A result of "community growth" (i.e., biofilms) may be to accumulate excess $\mathrm{C}$ and reducing equivalent as cells and exopolymer rather than internal storage molecules (e.g., lipid). Future work is needed to discern the differences between the physiological states of biofilm and free-living cells in multiple species.

It is possible that benthic microorganisms would prove more useful for biofilm growth modes, and we have recently grown a benthic diatom in biofilm reactors that could accumulate lipids (Fields, Whitney, and Valenzuela, unpublished results). These results suggest that the two growth modes can elicit different behaviors, and numerous research approaches and questions need to be explored to better understand the feasibility and cellular responses of microalgal biofilms for biomass and lipid accumulation.

\section{Ecological effects}

The literature offers many examples of increased lipid production in numerous algal species cultivated as monocultures 
in closed photobioreactor (PBR) or open raceway systems under varying nutrient limitations. However, as demonstrated by mathematical models and field experiments, phytoplankton biodiversity can be correlated to increased productivity (Tilman 1981; Downing and Leibold 2002; Striebel et al. 2009). Furthermore, in natural freshwater systems, productivity, measured as biomass, was highest when there was abundant nutrient availability (Interlandi and Kilham 2001). These observations underlie the challenge of needing high biomass loads to maximize overall lipid production. Obviously, productivity can fall under the guise of several metrics ranging from biomass, cell number, chlorophyll/pigments, and more recently, lipid accumulation. Despite the success of increased lipid content in nutrient-deprived monocultures, recent studies indicate that comparable lipid production can also be achieved in nutrient-rich systems with a diverse community.

A study by Stockenreiter et al. (2012) demonstrated increased lipid production in naturally occurring algal communities compared to that of single species cultivated in PBRs (Stockenreiter et al. 2012). For freshwater systems, P is the key nutrient responsible for eutrophication and can greatly alter productivity when limited (Schindler 1977; Smith and Bennett 1999; Schindler et al. 2008; Stockenreiter et al. 2012). Based upon observations with PBRs with deplete nutrient availability, one would expect to see substantially higher lipid content in the oligotrophic communities than the eutrophic. However, Stockenreiter et al. (2012) showed a linear increase in total algal lipid content in correlation with species richness of the examined communities and that lipid content in communities did not differ significantly from 22 laboratory monocultures $\left(1.4 \times 10^{6}\right.$ versus $\left.3.3 \times 10^{6} \mathrm{pg} \mathrm{ml}^{-1}\right)$. Although in no way conclusive, results such as these suggest comparable lipid values in nutrient replete and deplete systems and indicate the need to further investigate the relationship between nutrient type and abundance in the context of lipid production in mixed communities (Stockenreiter et al. 2013).

A diverse community is also more resistant to invasion from other species that could outcompete the desired algal species (Tilman 1977, 1981). Higher nutrient availability may also aid in algal cultivation by making algae less susceptible to viral infection. Coupled with community diversity, the relative health of each species is an important component. "Healthy" algae (i.e., cells not under nutrient stress) can be more resistant to viral infection that leads to cell lysis (Murray 1995). Rhodes and Martin (2010) developed a theoretical model that implicated high-nutrient availability in significantly reduced viral infection, and such scenarios will be important to consider in microalgal cultivation processes.

In contrast, despite the success of increased lipid accumulation in PBR monocultures under nutrient-limiting conditions, economic assessments indicate that PBRs operating on a large scale may not be commercially viable (Smith 2009). However, some have argued for hybrid systems that utilize a combination of both closed and open systems (Singh and Dhar 2011), or modified PBRs such as solid-state reactors (Naumann et al. 2013). In addition, if ponds are not well mixed, biomass loss due to dark respiration may impact performance for some microalgae (Huesemann et al. 2013). The ecology of open and closed systems will have different parameters and inputs that need to be considered in order to control and optimize ecosystem function (e.g., biomass, lipids, high value compounds). Therefore, life cycle analyses should help direct research to identify complementarity between water footprint, nutrient sources, regional light availability, process design, and targeted lipid-producing organisms.

Integrating life cycle analysis

Algal biofuels have the potential to provide a substantial fraction of US transportation fuel while imposing a relatively small (arable) land footprint (Sander and Murthy 2010) and providing opportunities for reducing water and nutrient consumption relative to first generation biofuels (Clarens et al. 2011). The degree to which biology and engineering can contribute to these goals will, however, be a function of the entire life cycle (Zaimes and Khanna 2013). A circumscribed version of that life cycle consistent with this review, one involving only the production cycle (distinct from the usage cycle), includes microbial growth, dewatering/drying, extraction/conversion energy/input recovery stages, with each stage involving a number of choices (Fig. 3).

With respect to benefits, life cycle analysis (LCA) has promoted system optimization by highlighting processing alternatives that produce a net increase in system performance, while also avoiding environmental "burden shifting" that can be obscured when viewing the production system less holistically (Klöpffer 1997). In addition, the growth stage will be significantly affected by choices made in the other three production stages, with the extraction/conversion technology having particular importance (Brennan and Owende 2010). While each has respective strengths and weaknesses, two of the most critical distinctions from a life cycle perspective are (a) the degree of pre-conversion drying required (Lardon et al. 2009) and (b) whether the conversion process involves all of the algal biomass or only the lipid fraction (Kirrolia et al. 2013).

The dependence of transesterification processes on algal lipid content can impose extra costs in the growth stage (Brennan and Owende 2010), and lipid accumulation procedures typically come at the cost of algal productivity (Davis et al. 2011). As noted by Quinn et al. (2013) and Chowdhury et al. (2012), increasing lipid content can result in an increase in processing greenhouse gas (GHG) emissions, because less residual biomass is used in a potential energy recovery stage. Thus, the grid energy requirement increases proportionally with the lipid fraction. Wet extraction transesterification 

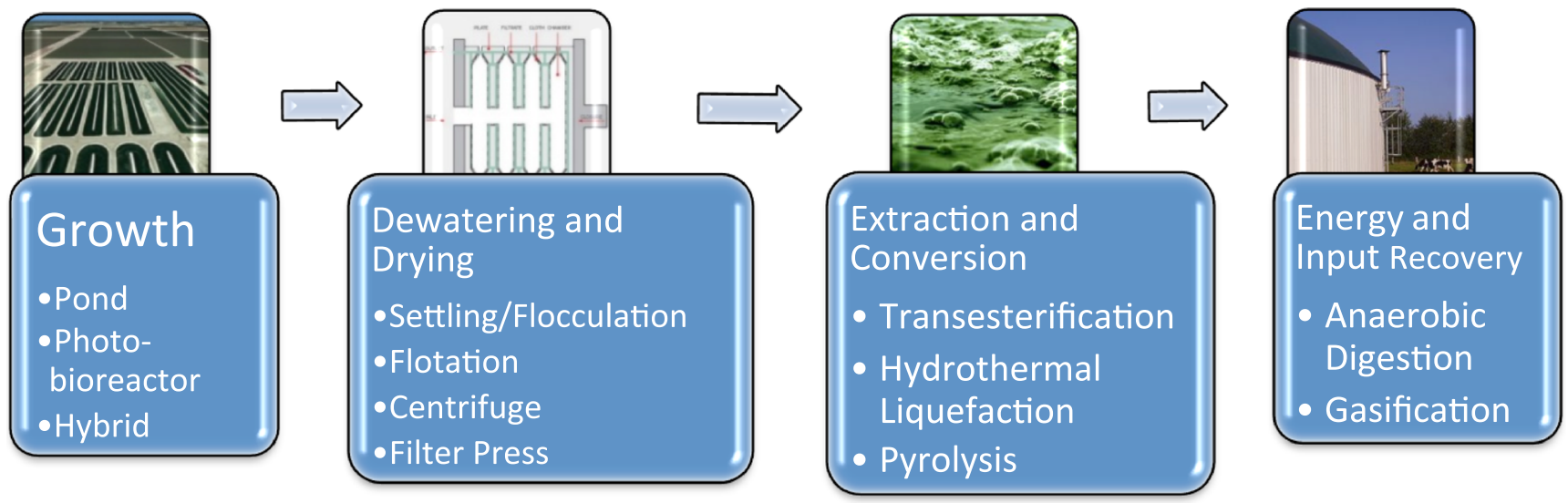

Fig. 3 Primary stages and (alternative processes) in the microalgae to fuel production process

processes, while significantly reducing the drying energy input, typically involve solvent-based extractions that lead to concerns over solvent disposal (Torres et al. 2013). In addition, solvent recycling can be challenging and energy intensive due to the high volumes and accompanying wet slurry (Ríos et al. 2013). Simultaneous extraction and transesterification processes (i.e., "reactive extraction") offer the potential for increased oil yields and lower process costs (Rawat et al. 2013), but the effectiveness of these processes at an industrial scale is still untested (Nagarajan et al. 2013).

Hydrothermal liquefaction (HTL) processes, despite greater capital expense, also reduce drying/dewatering requirements through the utilization of a wet feedstock (López Barreiro et al. 2013), while converting up to $60 \%$ of the total biomass into a useable fuel (Liu et al. 2013). As a result, HTL can increase fuel yields relative to transesterification (Frank et al. 2013), and this technology may reduce the importance of advanced culturing methods to enhance algal lipid accumulation for biofuel production (Elliott et al. 2013). However, thermochemical conversion methods such as HTL make nutrient recycling less efficient, as the nutrient-rich byproducts are poorly suited for direct recycling into the growth process or anaerobic digestion (López Barreiro et al. 2013). In addition, $\mathrm{N}$ loss during the conversion process results in a substantially increased nutrient requirement in the growth stage (Liu et al. 2013).

When attempting to assess the economic competitiveness of algal biofuels, an important source of uncertainty in existing studies is the extrapolation of lab and pilot-scale data to industrial scale production (Collet et al. 2013). The use of harmonization procedures (Sun et al. 2011) to reduce variability between multiple studies has allowed for more direct comparison of similar production frameworks given different assumptions. By harmonizing results from several sources, the base cost of production converged to $\$ 11.57 \mathrm{gal}^{-1}$ with a standard deviation of $\$ 1.17 \mathrm{gal}^{-1}$, this from a preharmonization value of $\$ 19.10 \mathrm{gal}^{-1}$ and a standard deviation of $\$ 6.22 \mathrm{gal}^{-1}$ (Slade and Bauen 2013). Given energy content, algae are predicted to require a production cost of $\$ 2.83 \mathrm{gal}^{-1}$ to be competitive with petroleum-based fuels (based on March 2014 oil prices) (Chisti 2007). However, many technological advances must occur to reach this point, and one issue that has received significant attention is the choice of microbial growth technology.

A wide range of different, and often contradicting, results have arisen from economic comparisons of microbial growth via open raceway ponds (ORPs) and photobioreactors (PBRs). The scale-up of PBRs is challenged by proper gas exchange and $\mathrm{pH}$ maintenance, but has mostly been discouraged by concerns over higher capital expense (Rawat et al. 2013). The latter has often led to pessimism regarding the use of PBRs for large-scale algae production, but recent studies have suggested that the higher productivity resulting from control of growth parameters leads to lower overall costs than those observed with ORPs (Norsker et al. 2011). Economies of scale arising from increasing production will also continue to reduce costs, and Acién et al. (2012) observed that increasing production by a factor of $50 \mathrm{de}-$ creased production cost per gallon by a factor of 5. Other studies have found that systems making use of a hybridized approach, involving both PBRs (for inoculation) and ORPs (for large-scale production and lipid accumulation) (Brennan and Owende 2010; Quinn et al. 2013), have the potential to greatly improve the cost competitiveness of algal biofuels. In all cases, however, the costs of inputs weigh heavily in the determination of overall production costs. Consequently, there is considerable interest in the impacts of co-location scenarios that involve low cost (or no cost) opportunities to acquire $\mathrm{CO}_{2}$ (e.g., via flue gas from power generation) as well as water and nutrients (e.g., municipal or agricultural wastewater). Access to these low-cost inputs can combine to decrease production costs by more than $50 \%$ (Fernandez et al. 2012); however, physiological issues related to growth on these nutrient sources (Kirrolia et al. 2013) and colocation challenges (Liu et al. 2013) continue to require further research. 
Life cycle analysis has been, and continues to be, successfully utilized to identify optimal algal biofuel production pathways. Ongoing refinement and application of this analytical technique can lead to advances that will guide future research toward a better understanding of the implications of many important choices, and thereby promote the development of more cost-effective and environmentally benign biofuel production processes. LCA has successfully identified synergies and tradeoffs between the growth stage and other parts of the production process, and results suggest that parallel research efforts involving both experimental research and life-cycle modeling can be effective (Collet et al. 2013).

\section{Conclusion}

With the reinvigorated interest in alternative fuels, microalgae provide one option that will likely contribute to an overall plan for biomass, biochemical, and biofuel production in a more sustainable and efficient manner. Given the typical ratio of $\mathrm{C} / \mathrm{N} / \mathrm{P}$ in microalgal biomass $\left(\mathrm{C}_{106} / \mathrm{N}_{16} / \mathrm{P}_{1}\right)$, much of the research has focused on $\mathrm{N}$ and $\mathrm{P}$ ( $\mathrm{P}$ to a lesser extent) and these two elements are linked in different ways to $\mathrm{C}$ through resource allocation at the cellular, population, and community levels. In addition, the supply of $\mathrm{C}$ either as $\mathrm{CO}_{2}$ or bicarbonate at critical times in the growth cycle can significantly improve lipid and biomass productivity. Micronutrients also play a role in cellular responses and activity, and $\mathrm{Si}$ and $\mathrm{Fe}$ need to be further studied with respect to $\mathrm{C} / \mathrm{N} / \mathrm{P}$ ratios and the allocation of $\mathrm{C}$ into desired compounds (e.g., lipids). Diatoms have potential for important contributions to lipid and biomass production but are less studied than the green algae. Many of the nutrient-deprived states have been studied with monocultures (or nearly axenic) as suspended cultures, and regardless of the systems used (e.g., closed reactors vs. open ponds), communities will assemble with different characteristics of stability, resiliency, and productivity. In addition, biofilms will likely develop, and may even be desired for the traits of accumulated biomass that can provide advantages for harvesting.

Moreover, while not directly covered in this mini-review, other resources/conditions will affect the cultivation of microalgae and include water, climate (e.g., light and temperature), land, and location (i.e., geography). Water will be essential for any biological process, and the water recycle will be crucial as many parts of the globe become increasingly stressed for potable water. Light is obviously an important parameter for phototrophs, and is inherently related to temperature as the need for light energy and heat-regulation scale at different proportions. Land is an essential commodity whether bioreactors or ponds are used and should not compete with agricultural needs. The location of growth and processing facilities are crucial aspects to be considered via LCA both for economic implications as well as the biology/ecology (e.g., biogeography) that can differ from region to region. Therefore, targeted science and engineering research is needed to better inform life cycle analyses and process design to maximize productivity, efficiency, and cost ratios.

Acknowledgments The authors would like to thank all members of the MSU Algal Biofuels Group for their helpful discussions. Support was provided by the US Department of Energy-Advancements in Sustainable Algal Production (ASAP) program under contract DE-EE0005993 and the National Science Foundation Sustainable Energy Pathways (SEP) Program under NSF CHE-1230632. We also would like to acknowledge student support from the Molecular Biosciences Program at Montana State University and the NSF IGERT Program in Geobiological Systems (DGE 0654336).

Open Access This article is distributed under the terms of the Creative Commons Attribution License which permits any use, distribution, and reproduction in any medium, provided the original author(s) and the source are credited.

\section{References}

Acién FG, Fernández JM, Magán JJ, Molina E (2012) Production cost of a real microalgae production plant and strategies to reduce it. Biotechnol Adv 30:1344-1353

Allen AE, LaRoche J, Maheswari U, Lommer M, Schauer N, Lopez PJ, Finazzi G, Fernie AR, Bowler C (2008) Whole-cell response of the pennate diatom Phaeodactylum tricornutum to iron starvation. Proc Natl Acad Sci U S A 105:10438-10443

Aslan S, Kapdan IK (2006) Batch kinetics of nitrogen and phosphorus removal from synthetic wastewater by algae. Ecol Eng 28:64-70

Atta M, Idris A, Bukhari A, Wahidin S (2013) Intensity of blue LED light: a potential stimulus for biomass and lipid content in fresh water microalgae Chlorella vulgaris. Bioresour Technol 148:373-378

Avendaño-Herrera RE, Riquelme CE (2007) Production of a diatombacteria biofilm in a photobioreactor for aquaculture applications. Aquac Eng 36:97-104

Bernstein HC, Kesaano M, Moll K, Smith T, Gerlach R, Carlson RP, Miller CD, Peyton BM, Cooksey KE, Gardner RD, Sims RC (2014) Direct measurement and characterization of active photosynthesis zones inside wastewater remediating and biofuel producing microalgal biofilms. Bioresource Technol (in press)

Bertozzini E, Galluzzi L, Ricci F, Penna A, Magnani M (2013) Neutral lipid content and biomass production in Skeletonema marinoi culture in response to nitrate limitation. Appl Biochem Biotechnol 170: $1624-1636$

Brennan L, Owende P (2010) Biofuels from microalgae - a review of technologies for production, processing, and extractions of biofuels and co-products. Renew Sust Energ Rev 14:557-577

Breuer G, Lamers PP, Martens DE, Draaisma RB, Wijffels RH (2012) The impact of nitrogen starvation on the dynamics of triacylgycerol accumulation in nine microalgae strains. Bioresour Technol 124: 217-226

Brown AP, Slabas AR, Rafferty JB (2009) Fatty acid biosynthesis in plants-metabolic pathways, structure and organization. In: Govindjee, Wada H, Murata N (eds) Lipids in photosynthesis: essential and regulatory functions, 30th edn., pp 11-34

Buesseler KO, Andrews JE, Pike SM, Charette MA (2004) The effects of iron fertilization on carbon sequestration in the southern ocean. Science 304:414-417 
Burrows EH, Bennette NB, Carrieri D, Dixon JL, Brinker A, Frada M, Baldassano SN, Falkowski PG, Dismukes GC (2012) Dynamics of lipid biosynthesis and redistribution in the marine diatom Phaeodactylum tricornutum under nitrate deprivation. BioEnergy Res 5:876-885

Chisti Y (2007) Biodiesel from microalgae. Biotechnol Adv 25(3):294-306 Chowdhury R, Viamajala S, Gerlach R (2012) Reduction of environmental and energy footprint of microalgal biodiesel production through material and energy integration. Bioresour Technol 108:102-111

Christenson LB, Sims RC (2012) Rotating algal biofilm reactor and spool harvester for wastewater treatment with biofuels by-products. Biotechnol Bioeng 109:1674-1684

Chu F, Chu P, Cai P, Li W, Lam PKS, Zeng RJ (2013) Phosphorus plays an important role in enhancing biodiesel productivity of Chlorella vulgaris under nitrogen deficiency. Bioresour Technol 134:341-346

Clarens AF, Resurreccion EP, White MA, Colosi LM (2011) Environmental life cycle comparison of algae to other bioenergy feedstocks. Environ Sci Technol 44:1813-1819

Collet P, Spinelli D, Lardon L, Hélias A, Steyer JP, Bernard O (2013) Life-cycle assessment of microalgal-based biofuels. Biofuels Algae 287-312

Courchesne NMD, Pariesien A, Wang B, Lan CQ (2009) Enhancement of lipid production using biochemical, genetic and transcription factor engineering approaches. J Bacteriol 141:31-41

Darley WM, Volcani BE (1969) Role of silicon in diatom metabolism: a silicon requirement for deoxyribonucleic acid synthesis in the diatom Cylindrotheca fusiformis Reimann and Lewin. Exp Cell Res 58: 334-342

Davis R, Aden A, Pienkos PT (2011) Techno-economic analysis of autotrophic microalgae for fuel production. Appl Energy 88:3524-3531

Dismukes GC, Carrieri D, Bennettee N, Ananyez GM, Posewitz MC (2008) Aquatic phototrophs: efficient alternatives to land-based crops for biofuels. Curr Opin Biotechnol 19:235-240

Downing AL, Leibold MA (2002) Ecosystme consequences of species richness and composition in pond food webs. Nature 416:837-841

Dukes JS (2003) Burning buried sunshine: human consumption of ancient solar energy. Clim Chang 61:31-44

Elliott DC, Neuenschwander GC, Hart TR (2013) Hydroprocessing biooil and products separation for coke production. ACS Sustain Chem Eng 1:389-392

Eustance E, Gardner RD, Mole KM, Menicucci J, Gerlach R, Peyotn BM (2013) Growth, nitrogen utilization, and biodiesel potential for two chlorophytes grown on ammonium, nitrate, or urea. J Appl Phycol 25:1663-1677

Feng P, Deng Z, Fan L, Hu Z (2012) Lipid accumulation and growth characteristics of Chlorella zofingiensis under different nitrate and phosphate concentrations. J Biosci Bioeng 114:405-410

Fernandez GA, González-López CV, Fernández Sevilla JM, Molina Grima E (2012) Conversion of $\mathrm{CO}_{2}$ into biomass by microalgae: how realistic a contribution may it be to significant $\mathrm{CO}_{2}$ removal? Appl Microbiol Biotechnol 57:96-586

Frank ED, Elgowainy A, Han J, Wang ZC (2013) Life cycle comparison of hydrothermal liquefaction and lipid extraction pathways to renewable diesel from algae. Mitig Adapt Strateg Glob Chang 18:137-158

Gardner R, Peters P, Peyton BM, Cooksey KE (2011) Medium pH and nitrate concentration effects on accumulation of triacylglycerol in two members of the chlorophyta. J Appl Phycol 23:1005-1016

Gardner R, Cooksey KE, Mus F, Macur R, Moll K, Eustance E, Carlson RP, Gerlach R, Fields MW, Peyton BM (2012) Use of sodium bicarbonate to stimulate triacylglycerol accumulation in the chlorophyte Scenedesmus sp. and the diatom Phaeodactylum tricornutum. J Appl Phycol 24:1311-1320

Georgianna DR, Mayfield SP (2012) Exploiting diversity and synthetic biology for the production of algal biofuels. Nature 488:329-335

Gordon JM, Polle JEW (2007) Ultrahigh bioproductivity from algae. Appl Microbiol Biotechnol 76:969-975
Greenwell HC, Laurens LML, Shields RJ, Lovitt RW, Flynn KJ (2010) Placing microalgae on the biofuels priority list: a review of the technological challenges. J R Soc Interface 7:703-726

Halsey KH, O’Malley RT, Graff JR, Milligan AJ, Behrenfeld MJ (2013) A common partitioning strategy fro photosynthetic products in evolutionary distinct phytoplankton species. New Phytol 198:1030-1038

Hildebrand M, Davis AK, Smith SR, Traller JC, Abbriano R (2012) The place of diatoms in the biofuels industry. Biofuels 3:221-240

Hoffmann JP (2002) Wastewater treatment with suspended and nonsuspended algae. J Phycol 34:757-763

Hu Q, Sommerfeld M, Jarvis E, Ghirardi M, Posewitz M, Seibert M, Valenzuela AD (2008) Microalgal triacylglycerols as feedstocks for biofuel production: perspectives and advances. Plant J 54:621-639

Huesemann MH, Van Wagenen J, Miller T, Chavis A, Hobbs S, Crowe B (2013) A screening model to predict microalgae biomass growth in photobioreactors and raceway ponds. Biotechnol Bioeng 110:15831594

Interlandi SJ, Kilham SS (2001) Limiting resources and the regulation of diversity in phytoplankton communities. Ecology 82:1270-1282

Irving TE, Allen DG (2011) Species and material considerations in the formation and development of microalgal biofilms. Appl Microbiol Biotechnol 92:283-294

Johnson MB, Wen Z (2010) Development of an attached microalgal growth system for biofuel production. Appl Microbiol Biotechnol 85:525-534

Khozin-Goldberg I, Cohen Z (2006) The effect of phosphate starvation on the lipid and fatty acid composition of the fresh water eustigmatophyte Monodus subterraneus. Phytochemistry 67:696-701

Kirrolia A, Bishnoi NR, Singh R (2013) Microalgae as a boon for sustainable energy production and its future research and development aspects. Renew Sustain Energy Rev 20:642-656

Klöpffer W (1997) Life cycle assessment. Environ Sci Pollution Res 4: 223-228

Kothari R, Pathak VV, Kumar V, Singh DP (2012) Experimental study for growth potential of unicellular alga Chlorella pyrenoidosa on diary wastewater: an integrate approach for treatment and biofuel production. Bioresour Technol 116:466-470

Kothari R, Prasad R, Kumar V, Singh DP (2013) Production of biodiesel from microalgae Chlamydomonas polypyrenoideum grown on dairy industry wastewater. Bioresour Technol 144:499-503

Kroger N, Poulsen N (2008) Diatoms, from cell wall biogenesis to nanotechnology. Ann Rev Genet 42:83-107

Lardon L, Helias A, Sialve B, Steyer JP, Bernard O (2009) Life-cycle assessment of biodiesel production from microalgae. Environ Sci Technol 43:6475-6481

Li T, Wan LL, Li AF, Zhang CW (2013) Responses in growth, lipid accumulation, and fatty acid composition of four oleaginous microalgae to different nitrogen sources and concentrations. Chin J Oceanol Limnol 31:1306-1314

Liang K, Zhang Q, Gu M, Cong W (2012) Effect of phosphorus on lipid accumulation in freshwater microalga Chlorella sp. J Appl Phycol 25:311-318

Liu X, Saydeh B, Ernki P, Colosi LM, Greg MB, Rhoses J, Clarens AF (2013) Pilot-scale data provide enhanced estimates of the life cycle energy and emissions profile of algae biofuels produced via hydrothermal liquefaction. Bioresour Technol 148:163-171

Lohman EJ, Gardner RD, Halverson L, Peyton BM, Gerlach R (2013) Carbon partitioning in lipids synthesized by Chlamydomonas reinhardtii when cultured under three unique inorganic carbon regimes. Bioresource Technol (in press)

Lombardi A, Wangersky P (1991) Influence of phosphorus and silicon on lipid class production by the marine diatom Chaetoceros gracilis grown in turbidostat cage cultures. Mar Ecol Prog Oldendorf 77:39-47

López Barreiro DL, Prins W, Ronsse F, Brilman W (2013) Hydrothermal liquefaction (HTL) of microalgae for biofuel production: state of the art review and future prospects. Biomass Bioenergy 53:113-127 
Mallick N (2002) Biotechnological potential of immobilized algae for wastewater N, P, and metal removal: a review. BioMetals 15:377390

McGinnis K, Dempster T, Sommerfeld M (1997) Characterization of the growth and lipid content of the diatom Chaetoceros muelleri. J Appl Phycol 9:19-24

Moll KM, Gardner RD, Eustance EO, Gerlach R, Peyton BM (2014) Combining multiple nutrient stresses and bicarbonate addition to promote lipid accumulation in diatoms. Algal Res (accepted with revisions)

Morel FMM, Rueter JG, Price NM (1991) Iron nutrition of phytoplankton and its possible importance in the ecology of ocean regions with high nutrient and low biomass. Oceanography 4:56-61

Msanne J, Xu D, Konda AR, Casas-Mollano JA, Awada T, Cahoon EB, Cerutti H (2012) Metabolic and gene expression changes triggered by nitrogen deprivation in the photoautotrophically grown microalgae Chlamydomonas reinhardtii and Coccomyxa sp. C-169. Phytochemistry 75:50-59

Murray AG (1995) Phytoplankton exudation - exploitation of the microbial loop as a defense against algal viruses. J Plankton Res 17:10791094

Mus F, Toussaint J, Cooksey KE, Fields MW, Gerlach R, Peyton BM, Carlson RP (2013) Physiological and molecular analysis of carbon source supplementation and $\mathrm{pH}$ stress-induced lipid accumulation in the marine diatom Phaeodactylum tricornutum. Appl Microbiol Biotechnol 97:3625-3642

Nagarajan S, Chou SK, Cao SY, Wu C, Zhou Z (2013) An updated comprehensive techno-economic analysis of algae biodiesel. Bioresour Technol 145:150-156

Naumann T, Cebi Z, Podola B, Melkonian M (2013) Growing microalgae as aquaculture feeds on twin-layers: a novel solid-state photobioreactor. J Appl Phycol 25:1413-1420

Norsker NH, Barbosa MJ, Vermuë MH, Wijffels RH (2011) Microalgal production - a close look at the economics. Biotechnol Adv 29:24 27

Obata T, Fernie AR, Nunes-Nesi A (2013) The central carbon and energy metabolism of marine diatoms. Metabolites 3:325-346

Odum EP (1985) Trends expected in stressed ecosystems. Bioscience 35: $419-422$

Odum EP, Finn JT, Franz EH (1979) Perturbation theory and the subsidystress gradient. Bioscience 29:349-352

Olson RJ, Vaulot D, Chisholm SW (1986) Effects of environmental stresses on the cell cycle of two marine phytoplankton species. Plant Physiol 80:918-925

Ozkan A, Kinney K, Katz L, Berberoglu H (2012) Reduction of water and energy requirement of algae cultivation using an algae biofilm photobioreactor. Bioresour Technol 114:542-548

Palmqvist K, Sjöberg S, Samuelsson G (1988) Induction of inorganic carbon accumulation in the unicellular green algae Scenedesmus obliquus and Chlamydomonas reinhardtii. Plant Physiol 87:437442

Pate R, Klise G, Wu B (2011) Resource demand implications for US algae biofuels production scale-up. Appl Energy 88:3377-3388

Patil JS, Anil AC (2005) Biofilm diatom community structure: influence of temporal and substratum variability. Biofouling 21:189-206

Pittman JK, Dean AP, Osundeko O (2011) The potential of sustainable algal biofuel production using wastewater resources. Bioresour Technol 102:17-25

Quinn JC, Catton KB, Johnson S, Bradley TH (2013) Microalgae to biofuels lifecycle assessment-multiple pathway evaluation. Bioenergy Res 6:591-600

Ratha SK, Babu S, Renuka N, Prasanna R, Prasad RBN, Saxena AK (2013) Exploring nutritional modes of cultivation for enhancing lipid accumulation in microalgae. J Basic Microbiol 53:440-450

Raven JA (1983) The transport and function of silicon in plants. Biol Rev 58:179-207
Rawat I, Kumar RR, Mutanda T, Bux F (2013) Biodiesel from microalgae: a critical evaluation from laboratory to large-scale production. Appl Energy 103:444-467

Razghefard R (2013) Algal biofuels. Photosynth Res 117:207-219

Redfield A (1958) The biological control of chemical factors in the environment. Am Sci 46:205-211

Ren HY, Liu BF, Ma C, Zhao L, Ren NQ (2013) A new lipid-rich microalgae Scenedesmus strain R-16 isolated using Nile Red staining: effects of carbon and nitrogen sources and initial $\mathrm{pH}$ on the biomass and lipid production. Biotechnol Biofuels 6:143

Rhodes CJ, Martin AP (2010) The influence of viral infection on a plankton ecosystem undergoing nutrient enrichment. J Theo Biol 265:225-237

Ríos SD, Torres CM, Torras C, Salvado J, Maeo-Sanz JM, Jimenez L (2013) Microalgae-based biodiesel: economic analysis of downstream process realistic scenarios. Bioresour Technol 136:617-625

Roessler PG (1988) Effects if silicon deficiency in lipid composition and metabolism in the diatom Cyclotella cryptica. J Phycol 24:394-400

Sander K, Murthy GS (2010) Life cycle analysis of algae biodiesel. Int J Life Cycle Assess 15(7):704-714

Schindler DW (1977) Evolution of phosphorus limitation in lakes. Science 195:260-262

Schindler DW, Wolfe AP, Vinebrooke R, Crowe A, Blais JM, Miskimmin B, Freed R, Perren B (2008) The cultural eutrophication of Lac la Biche, Alberta, Canada: a paleoecological study. Can J Fish Aquat Sci 65:2211-2223

Schnurr PJ, Espie GS, Allen DG (2013) Algae biofilm growth and the potential to stimulate lipid accumulation through nutrient starvation. Bioresour Technol 136:337-344

Schuhmann H, Lim DKY, Schenk PM (2012) Perspectives on metabolic engineering for increased lipid contents in microalgae. Biofuels 3:71-86

Sharma KK, Schuhmann H, Schenk PM (2012) High lipid induction in microalgae for biodiesel production. Energies 5:1532-1553

Sheehan J, 1998. A look back at the US Department of Energy's aquatic species program (NREL/TP-580-24190)

Shekh AY, Shrivastava P, Krishnamurthi K, Mudliar SN, Devi SS, Kanade GS, Lokhande SK, Chakrabarti T (2013) Stress-induced lipids are unsuitable as a direct biodiesel feedstock: a case study with Chlorella pyrenoidose. Bioresour Technol 138:382-386

Singh NK, Dhar DW (2011) Microalgae as second generation biofuel. Agron Sustain Dev 31:605-629

Slade R, Bauen A (2013) Micro-algae cultivation for biofuels: cost, energy balance, environmental impacts and future prospects. Biomass Bioenergy 53:29-38

Smith SR (2009) Organic contaminants in sewage sludge and their significance for agricultural recycling. Phil Trans Royal Soc A Math Phy Eng Sci 367:4005-4041

Smith VH, Bennett SJ (1999) Nitrogen:phosporus supply ratios and phytoplankton community structure in lakes. Arch Hydrobiol 146: $37-53$

Smith SR, Abbriano RM, Hildebrand M (2012) Comparative analysis of diatom genomes reveals substantial differences in the organization of carbon partitioning pathways. Algal Res 1:2-16

Spalding MH (2008) Microalgal carbon-dioxide-concentrating mechanisms: Chlamydomonas inorganic carbon transporters. J Exp Bot 59:1463-1473

Stockenreiter M, Graber AK, Haupt F, Stibor H (2012) The effect of species diversity on lipid production by microalgal communities. J Appl Phycol 24:45-54

Stockenreiter M, Haupt F, Graber AK, Seppala J, Spilling K, Tamminen T, Stibor H (2013) Functional group richness: implications of biodiversity for light use and lipid yield in microalgae. J Phycol 49: 838-847

Striebel M, Behl S, Stibor H (2009) The coupling of biodiversity and productivity in phytoplankton communities: consequences for biomass stoichiometry. Ecology 90:2025-2031 
Sun A, Davis R, Starbuck M, Ben-Amotz A, Pate R, Pienkos PT (2011) Comparative cost analysis of algal oil production for biofuels. Energy 36:5169-5179

Taguchi S, Hirata JA, Laws EA (1987) Silicate deficiency and lipid synthesis of marine diatoms. J Phycol 23:260-267

Tilman D (1977) Resource competition between planktonic algae-experimental and theoretical approach. Ecology 58: $338-348$

Tilman D (1981) Tests of resource competition theory using 4 species of Lake Michigan algae. Ecology 62:802-815

Torres CM, Rios SD, Torras C, Salvado J, Mateo-Sanz JM, Jimenez L (2013) Microalgae-based biodiesel: a multicriteria analysis of the production process using realistic scenarios. Bioresour Technol 147: $7-16$

Valenzuela J, Mazurie A, Carlson RP, Gerlach R, Cooksey KE, Peyton BM, Fields MW (2012) Potential role of multiple carbon fixation pathways during lipid accumulation in Phaeodactylum tricornutum. Biotechnol Biofuels 5:1-17

Valenzuela J, Carlson RP, Gerlach R, Cooksey KE, Peyton BM, Bothner B, Fields MW (2013) Nutrient re-supplementation arrests bio-oil accumulation in Phaeodactylum tricornutum. Appl Microbiol Biotechnol 97:7049-7059
Vaulot D, Olson R, Merkel S, Chisholm S (1987) Cell-cycle response to nutrient starvation in two phytoplankton species, Thalassiosira weissflogii and Hymenomonas carterae. Mar Biol 95:625-630

Wang ZT, Ullrich N, Joo S, Waffenschmidt S, Goodenough U (2009) Algal lipid bodies: stress induction, purification, and biochemical characterization in wild-type and starchless Chlamydomonas reinhardtii. Eukaryotic Cell 8:1856-1868

Whitman WB, Coleman DC, Wiebe WJ (1998) Prokaryotes: the unseen majority. Proc Natl Acad Sci U S A 95:6578-6583

Wu LF, Chen PC, Lee CM (2013) The effects of nitrogen sources and temperature on cell growth and lipid accumulation of microalgae. Int Biodeterior Biodegrad 85:506-510

Yang Y, Mininberg C, Tarbet A, Weathers P (2013) At high temperature lipid production in Ettlia oleoabundans occurs before nitrate depletion. Appl Microbiol Biotechnol 97:2263-2273

Yu E, Zendejas F, Lane P, Gaucher S, Simmons B, Lane T (2009) Triacylglycerol accumulation and profiling in the model diatoms Thalassiosira pseudonana and Phaeodactylum tricornutum (Baccilariophyceae) during starvation. J Appl Phycol 21:669-681

Zaimes GG, Khanna V (2013) Environmental sustainability of emerging algal biofuels: a comparative life cycle evaluation of algal biodiesel and renewable diesel. Environ Prog Sustain Energy 32:926-936 